\title{
Efficient Rhodamine B Removal Using Acid- and Alkaline-Activated Musa paradisiaca Biochar
}

\author{
Folahan A. Adekola ${ }^{1}$, Suleiman B. Ayodele ${ }^{1}$, Adejumoke A. Inyinbor ${ }^{2 *}$ \\ ${ }^{1}$ Industrial Chemistry Department, University of Ilorin, Ilorin, Nigeria \\ ${ }^{2}$ Physical Sciences Department, Landmark University, Omu Aran, Nigeria
}

Received: 2 May 2018

Accepted: 16 August 2018

\begin{abstract}
Musa paradisiaca char was subjected to acid and alkaline treatment in order to prepare highly porous and efficient adsorbents. Prepared adsorbents were subjected to various characterizations viz surface morphology using a scanning electron microscopic (SEM), surface functional group using the Fourier transformed infrared spectroscopic (FTIR) analysis, and Brunauer-Emmett-Teller (BET) surface area among others. Adsorbents were subsequently used for the uptake of Rhodamine B (RhB) from aqueous solution, and adsorption data were tested with isothermal and kinetics models. BET surface area of $985 \mathrm{~m}^{2} / \mathrm{g}$ was obtained for alkaline-treated Musa paradisiaca. SEM revealed large pores on treated biomass and functional groups analysis revealed functional groups suitable for sorption. The prepared adsorbents were found to be effective in the uptake of Rhodamine B, with more than $90 \%$ removal in some cases. Maximum adsorption was obtained at $\mathrm{pH} 4$ for both adsorbents. Equilibrium adsorption data fitted best into the Langmuir adsorption isotherm with maximum monolayer adsorption capacity of $7.003 \mathrm{mg} / \mathrm{g}$ and $6.878 \mathrm{mg} / \mathrm{g}$ for acid-treated biomass and alkaline-treated biomass, respectively. Pseudo second-order kinetics best described the adsorption kinetic data of the two adsorption systems.
\end{abstract}

Keywords: Musa paradisiaca, biomass, Rhodamine B, kinetics; isotherms

\section{Introduction}

Xanthene dyes, which is heavily used in various dyeing processes, contribute a great deal to environmental deterioration. Wastewater from a dye house usually contains molecules of spent dyes [1, 2]. Dye molecules are non-biodegradable, persist in the environment and can be sources of a range of diseases

*e-mail: inyinbor.adejumoke@landmarkuniversity.edu.ng when ingested by humans [3, 4]. The removal of xanthene dye from wastewater is therefore of utmost importance before their eventual discharge into the environment.

Effective treatment of wastewater containing xanthene dyes is almost impossible, both because of the nature of these dyes as well as challenges of techniques currently in use for wastewater treatment. Rhodamine B, for instance, is known to be highly soluble and passes through the conventional wastewater treatment methods without being affected [5]. Conventional methods of wastewater treatment also 
fail when the removal of very low concentrations of pollutants is required. Adsorption using expensive activated carbon, however, deals with very low concentrations of the pollutant [6].

Cost accumulates on activated carbon due to its precursor and production techniques, hence an alternate precursor as well as cheap processing techniques are been developed. Various precursors and methods are been explored for cheap and efficient activated carbon preparation [2, 7-9]. Precursors for activated carbon preparation should be carbon rich, and activation techniques determine their subsequent performance. Physical and chemical methods of activation are mainly used on carbon to improve their porosity and surface area [10]. The chemical methods take two routes: first, carbonization followed by chemical activation to generate micro- and mesopores; and second, chemical impregnation followed by thermal treatment, where carbonization and activation occur simultaneously. Whichever route, chemical activation saves energy consumption, and hence is economical compared with the physical activation technique [11]. Higher yield, better surface area and obtaining materials with surface functional groups are other advantages of the chemical method of activation over the physical method of activation [12]. Potassium hydroxide and orthophosphoric acid are a few highly efficient activating agents in use, and they usually give well-defined pores [13].

In this study, we used the peel of Musa paradisiaca, a biomass rich in carbon and a common waste that constitute a nuisance to the environment in our locale. This precursor was charred in order to enrich its carbon content. Subsequently, acid and alkaline activation were carried out on the charred material in order to establish the best activation technique.

\section{Materials and Methods}

\section{Sample Collection, Identification and Pretreatment}

Samples of plantain peel identified as Musa paradisiaca were collected from Ipata Market in Ilorin, Kwara State. In order to remove categories of impurities, samples were thoroughly washed under running tap and subsequently with distilled. Samples were dried in an oven controlled at $100^{\circ} \mathrm{C}$ for 24 hours. The dried sample was carefully pulverized and screened into particle size between 75 and $835 \mu \mathrm{m}$, kept in an airtight container and labelled PP.

\section{Reagents}

All reagents used in this study were of analytical grade and were used without further purification.

\section{Carbonization Process}

PP (20 g) was transferred into a silica crucible and heated in an air-tight furnace (Garbolite CWF 1300) operated at $500^{\circ} \mathrm{C}$ for 5 hours. Obtained carbon material were carefully transferred to an airtight container labelled PPC and kept for further treatment.

\section{PPC Activation}

Equal mass/volume ratio of $\mathrm{PPC}$ and $0.1 \mathrm{M} \mathrm{KOH}$ and $\mathrm{H}_{3} \mathrm{PO}_{4}$ were mixed in separate crucibles. Each crucible with its content was heated at $750 \pm 50^{\circ} \mathrm{C}$ for five minutes. Activated PPC samples were allowed to cool to room temperature and were subsequently washed with distilled water until neutral $\mathrm{pH}$ was obtained. It was dried in an oven operated at $110^{\circ} \mathrm{C}$ for 8 hours. $\mathrm{KOH}$-activated carbon was labelled PPCp while $\mathrm{H}_{3} \mathrm{PO}_{4}$-activated samples were labelled PPCo.

\section{Characterization of PPCp and PPCo}

The surface functional groups were obtained using a Bruker Alpha FTIR spectrometer. The surface morphology and surface characteristics were obtained using a Feiesem quanta 200 with EDS.

\section{Adsorbate Preparation}

Stock solution of $1000 \mathrm{mgL}^{-1}$ Rhodamine-B (RhB) was prepared by dissolving $1 \mathrm{~g}$ of $\mathrm{RhB}$ in $1000 \mathrm{~cm}^{3}$ of distilled-deionized water. All other working solutions of lower concentrations were prepared by serial dilution.

\section{Adsorption Studies}

Various adsorption operational parameters were given attention in this study. Adsorbent and adsorbate behavior as well as their performance and reactions depend greatly on parameters such as solution $\mathrm{pH}$, adsorbate concentration, adsorbent-adsorbate contact time, and temperature, as well as adsorbent dosage. This study covered the aforementioned operational parameters; initial solution $\mathrm{pH}(\mathrm{pH} 2-9)$, adsorbent dosage (0.01-0.2 g), initial RhB concentration (5-50 $\mathrm{mg} / \mathrm{L})$, contact time $(5-240$ minutes $)$ and temperature $(303-333 \mathrm{~K})$. Each desired $\mathrm{pH}$ was obtained via the addition of $0.1 \mathrm{M} \mathrm{HCl}$ or $0.1 \mathrm{M} \mathrm{NaOH}$. Each operational parameter study used $25 \mathrm{~cm}^{3}$ adsorbate in a $250 \mathrm{~cm}^{3}$ Erlenmeyer flask with varying parameters in study, while others were fixed. The mixture of adsorbate and adsorbent in a conical flask was properly sealed and agitated in a temperature-controlled water bath shaker. Samples were withdrawn at intervals depending on the study, centrifuged and the supernatant analyzed 
for unadsorbed dye using a Beckman Coulter Du 730 Life science UV-Visible Spectrophotometer operated at $554 \mathrm{~nm}$.

\section{Mathematical Analysis}

The quantity of $\mathrm{RhB}$ uptake and percentage $\mathrm{RhB}$ removal can be calculated using mathematical expressions 1 and 2 :

$$
\begin{gathered}
q_{t}=\frac{\left(C_{i}-C_{f}\right) v}{m} \\
\% \text { Removal }=\frac{\left(C_{i}-C_{f}\right)}{C_{i}} \times 100
\end{gathered}
$$

...where $\mathrm{q}_{t} \mathrm{C}_{\mathrm{i}}$ and $\mathrm{C}_{\mathrm{f}}$ are the quantity of RhB uptake in $\mathrm{mg} / \mathrm{g}$, and the initial and final concentrations in $\mathrm{mg} / \mathrm{L}$ respectively.

\section{Adsorption Data Analysis}

\section{Isothermal Studies}

Langmuir isotherm [14] describes the monolayer adsorption process. Equation (3) is an expression of Langmuir equation. Equation (3a) expresses the dimensionless constant $\mathrm{R}_{\mathrm{L}}$, which explains the favourability of the adsorption process. $\mathrm{C}_{\mathrm{e}}$ and $\mathrm{q}_{\mathrm{e}}$ are adsorbate concentration in solution at equilibrium measured $(\mathrm{mg} / \mathrm{L})$ and quantity of dye adsorbed at equilibrium in $\mathrm{mg} / \mathrm{g}$, respectively. $q_{\max }$ is the maximum monolayer adsorption capacity of adsorbent $(\mathrm{mg} / \mathrm{g})$ and $K_{\mathrm{L}}$ is the Langmuir adsorption constant (L/mg).

$$
\begin{gathered}
\frac{C_{e}}{q_{e}}=\frac{C_{e}}{q_{\max }}+\frac{1}{q_{\max } K_{L}} \\
\mathrm{R}_{L}=\frac{1}{\left(1+K_{L} C_{o}\right)}
\end{gathered}
$$

Freundlich isotherm [15] describes adsorption onto multiple surfaces, and it is expressed mathematically by Equation (4). $C_{e}$ and $q_{e}$ are as earlier defined. Freundlich constants $\mathrm{K}_{\mathrm{f}}$ and $\mathrm{n}$ cooperate with the factors affecting adsorption capacity and adsorption intensity, respectively.

$$
\log q_{e}=\frac{1}{n} \log C_{e}+\log K_{f}
$$

Temkin isotherm [16], which ignores extreme conditions, rather assumes linear than logarithm decrease of heat of adsorption. Equation (5) gives a mathematical expression of Temkin. A $(\mathrm{L} / \mathrm{g})$ and $\mathrm{B}$ are Temkin isotherm constants and $\mathrm{b}(\mathrm{J} / \mathrm{mol})$ is a constant related to the heat of absorption and can be determined using Equation (5a). Where $\mathrm{T}$ is the absolute temperature $(\mathrm{K})$ and $\mathrm{R}$ is the gas constant $(\mathrm{J} / \mathrm{mol} \mathrm{K})$.

$$
\begin{gathered}
q_{e}=B \ln A+B \ln C_{e} \\
B=R T /_{b}
\end{gathered}
$$

\section{Kinetics Model}

Kinetics models give better insight into the adsorption process and mechanism of adsorption. The established kinetics models, the pseudo first-order kinetics model of Lagergren [17], Ho and McKay pseudo second-order [18] and the Weber and Morris [19] intraparticle diffusion model were employed for kinetics data analysis. These give insight into the mechanisms of adsorption and have been widely used as tools to establish adsorption mechanisms for various aqueous adsorption process [20-22]. Equations (6-8) express the pseudo first-order kinetics model, pseudo secondorder kinetic model and intraparticle diffusion model by Weber and Morris, respectively:

$$
\begin{gathered}
\ln \left(q_{e}-q_{t}\right)=\ln q_{e}-k_{1} t \\
\frac{t}{q_{t}}=\frac{1}{k_{2} q_{e}^{2}}+\frac{t}{q_{e}} \\
q_{t}=k_{\text {diff }} t^{1 / 2}+C
\end{gathered}
$$

...where $\mathrm{q}_{\mathrm{e}}$ and $\mathrm{q}_{\mathrm{t}}$ are quantity of $\mathrm{RhB}$ adsorbed at equilibrium and at time $\mathrm{t}(\mathrm{mg} / \mathrm{g})$, respectively; $\mathrm{k}_{1}, \mathrm{k}_{2}$ and $\mathrm{k}_{\text {diff }}$ are the pseudo first-order rate constant $\left(\mathrm{min}^{-1}\right)$; pseudo first-order rate constant $\left(\mathrm{g} / \mathrm{mg} \mathrm{min}^{-1}\right)$ and the intraparticle diffusion constant in $\mathrm{mg} \mathrm{g}^{-1} \mathrm{~min}^{-1 / 2}$. $\mathrm{C}$ is the boundary layer thickness.

\section{Thermodynamic Studies}

The spontaneity, feasibility and adsorbateadsorbent interactions modes can be well understood via thermodynamic studies. $\Delta \mathrm{G}^{\circ}, \Delta \mathrm{H}^{\circ}$ and $\Delta \mathrm{S}^{\circ}$ were calculated using mathematical relations 9 and 10:

$$
\begin{aligned}
\ln K_{o} & =\frac{\Delta \mathrm{S}^{\circ}}{R}-\frac{\Delta \mathrm{H}^{\circ}}{R T} \\
\Delta \mathrm{G}^{\circ} & =-R T \ln K_{o}
\end{aligned}
$$

...where $\mathrm{T}$ is the temperature in Kelvin, $\mathrm{R}$ is the gas constant and $\mathrm{K}_{\mathrm{o}}$ can be obtained from equilibrium concentration and quantity adsorbed at equilibrium. The values of enthalpy $\left(\Delta \mathrm{H}^{\circ}\right)$ and $\Delta \mathrm{S}^{\circ}$ can be obtained from the plot of $\ln \mathrm{K}_{\mathrm{o}}$ versus $1 / \mathrm{T}$. 
Table 1. Characteristics of PPCo and PPCp.

\begin{tabular}{|c|c|c|}
\hline \multirow{2}{*}{ Parameters } & \multicolumn{2}{|c|}{ Values } \\
\cline { 2 - 3 } & PPCo & PPCp \\
\hline $\mathrm{pH}$ & 6.14 & 6.71 \\
\hline Bulk density & 0.83 & 0.80 \\
\hline Iodine value & 769 & 943 \\
\hline BET surface area $\left(\mathrm{m}^{2} / \mathrm{g}\right)$ & - & 985 \\
\hline Elemental composition $(\%)$ & & \\
\hline $\mathrm{C}$ & 79.94 & 77.59 \\
\hline $\mathrm{O}$ & 19.45 & 20.89 \\
\hline $\mathrm{K}$ & 0.61 & 0.39 \\
\hline $\mathrm{Ca}$ & - & 0.59 \\
\hline $\mathrm{Si}$ & - & 0.54 \\
\hline
\end{tabular}

\section{Results and Discussion}

\section{Physicochemical Characterization}

The various characteristics of prepared adsorbents are listed in Table 1. $\mathrm{pH}$ of the two adsorbent were recorded to be close to neutral, while high bulk density greatly characterized the two adsorbents. While BET surface area determination fell below detection limit for PPCo, values recorded for BET surface area and iodine value were very close for PPCp. The adsorbents were rich in carbon and oxygen and had traces of other elements. High bulk density obtained for both adsorbents suggests that adsorbents will likely have good contact with adsorbate molecules in solution. Low bulk density usually results in adsorbent flotation and reduces adsorbent contact with adsorbate molecules, hence reducing adsorbent performance [23]. BET surface area was obtained as $985 \mathrm{~m}^{2} / \mathrm{g}$ for PPCp, which is in close agreement with the iodine value obtained. The surface area for PPCo, however, was observed to be low.

\section{Surface Functional Group Analysis}

The spectrum of unactivated plantain peel carbon (PPC) showed the appearance of absorption band at $3300 \mathrm{~cm}^{-1}$ characteristics of $-\mathrm{OH}$ stretching vibration. This absorption band was observed to gradually disappear as biomass treatment move from carbonization to activation. Absorption bands between 1100 and $1200 \mathrm{~cm}^{-1}$ as well as 1500 and $1600 \mathrm{~cm}^{-1}$ were common across the three spectra presented. Peaks at around $1370 \mathrm{~cm}^{-1}$ and $2930 \mathrm{~cm}^{-1}$ present in PPC and PPCo were not vivid in PPCp. Carbonization and activation removes adventitious water, thus the gradual disappearance of $-\mathrm{OH}$ stretching vibration was observed at $3300 \mathrm{~cm}^{-1}$ [24]. The absorption bands between 1500 and $1600 \mathrm{~cm}^{-1}$ correspond to vibrations of $\mathrm{C}=\mathrm{C}$ of aromatic, while peaks observed at 1367 and $1368 \mathrm{~cm}^{-1}$ in PPC and PPCo respectively are characteristic vibrations of aromatic C-C bond. Carbonization may enhance aromatization of aliphatic groups.

\section{Surface Morphology}

The carbonized plantain peel present a moderately smooth surface without visible openings (Fig. 1a). Acid and $\mathrm{KOH}$ activation results in moderately large pores (mesopores) with rough cavities (Figs $1 \mathrm{~b}$ and 1c). Mesopores are suitable pore size required for the uptake
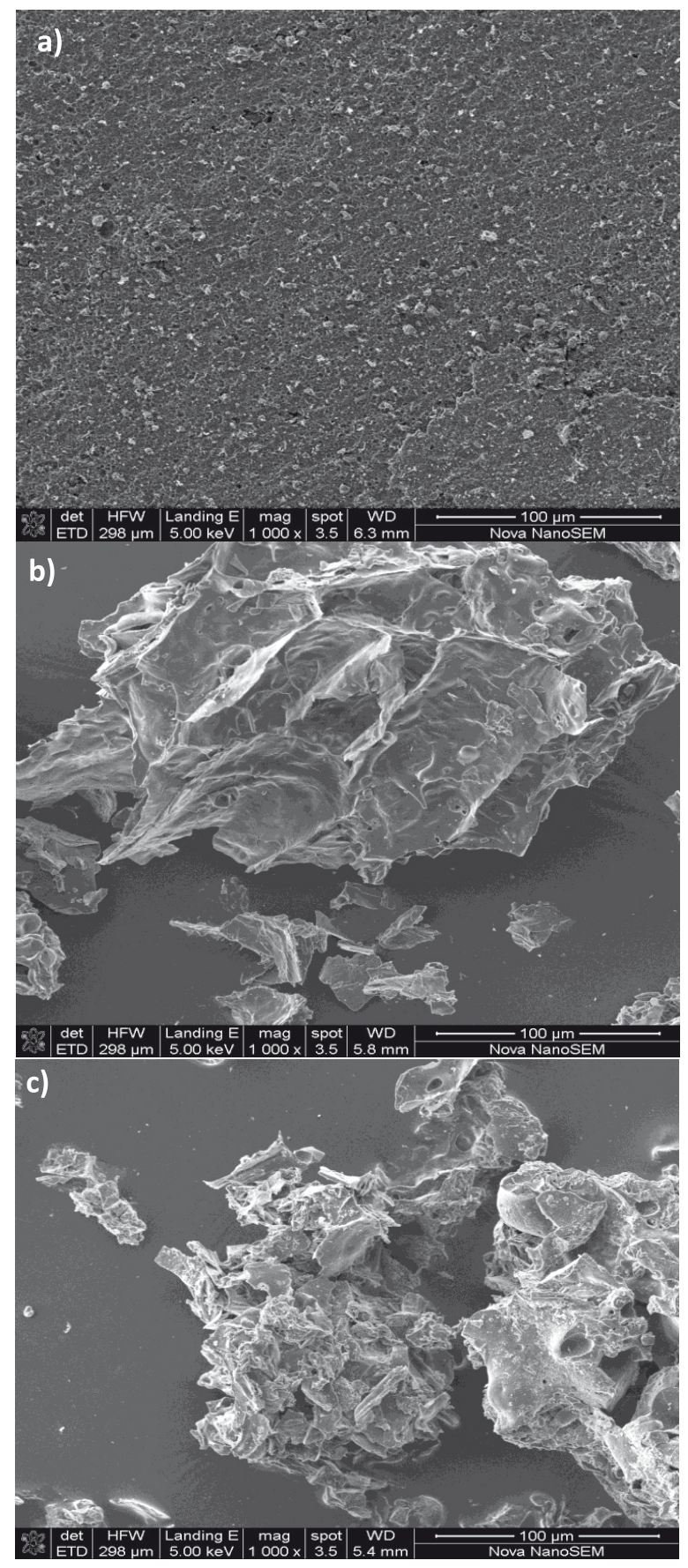

Fig. 1. Scanning electron micrograph of PPC a), PPCo b) and PPCp c). 


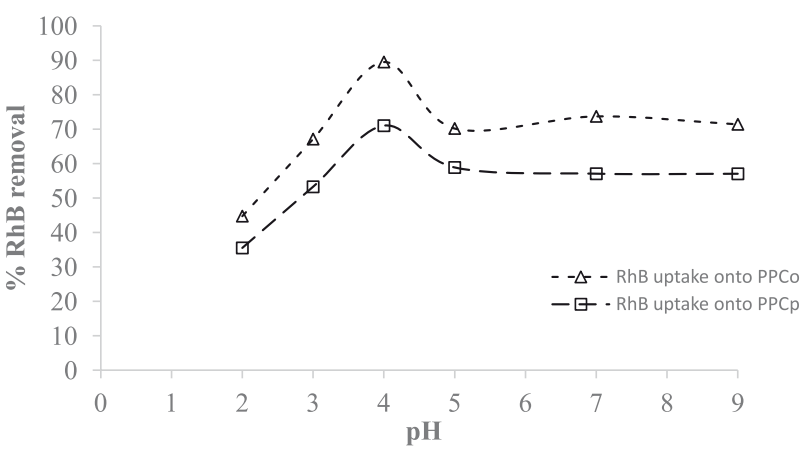

Fig. 2. Effects of $\mathrm{pH}$ on $\mathrm{RhB}$ uptake onto PPCo and PPCp [Dosage $(0.1 \mathrm{~g})$, Temperature $\left(26^{\circ} \mathrm{C}\right)$ and agitation speed (130 rpm)].

of large molecules such as dyes. Pores and cavities have the tendency to trap adsorbates, thus enhancing adsorbent adsorption efficiency. Previously reported work identified such pores and cavities as medium for dye removal [25].

\section{Effects of $\mathrm{pH}$ on $\mathrm{RhB}$ Adsorption onto PPCo and PPCp}

The percentage $\mathrm{RhB}$ adsorption rapidly rose from $35.51 \%$ through $53.26 \%$ as $\mathrm{pH}$ increased from 2 to 3 for PPCp, and optimum removal of $71.01 \%$ was obtained at $\mathrm{pH} 4$ (Fig. 2). Although better removal efficiency was observed for PPCp, removal followed the same trend with optimum percentage removal reaching $89.51 \%$. Adsorption percentage subsequently dropped as the $\mathrm{pH}$ further increased and no substantive difference was observed in the percentage of RhB removal for PPCo and PPCp at high $\mathrm{pH}$. Adsorbate solution $\mathrm{pH}$ greatly influences adsorbate behavior. RhB exhibits different forms depending on the solution $\mathrm{pH}$; cationic at $\mathrm{pH}$ range 1 to 3 , lactonic at $\mathrm{pH}$ lower than 1.0 and zwitterionic at $\mathrm{pH}$ greater than 3.7. The tendency exhibited by the zwitterionic form of RhB leads to its dimer formation, thus reducing adsorption potential at $\mathrm{pH}$ above 4 . Reports of maximum adsorption at $\mathrm{pH}$ between 3 and 4 exist in the literature $[3,24,26$, 27].

\section{Effects of Concentration on RhB Uptake onto PPCo and PPCp}

RhB uptake increased with increased concentrations. No distinct difference was noted in the uptake of PPCo and PPCp. The percentage of RhB removal of greater than $95 \%$ was obtained for the lowest concentration studies, while a little bit above $50 \%$ percentage removal was obtained for the highest concentration studied. Quantity RhB adsorbed at equilibrium rose from $3.79 \mathrm{mg} / \mathrm{g}$ for $5 \mathrm{mg} / \mathrm{L}$ concentration to $43.16 \mathrm{mg} / \mathrm{g}$ for $50 \mathrm{mg} / \mathrm{L}$ concentration for PPCo and $3.76 \mathrm{mg} / \mathrm{g}$ for $5 \mathrm{mg} / \mathrm{L}$ concentration to $43.21 \mathrm{mg} / \mathrm{g}$ for $50 \mathrm{mg} / \mathrm{L}$ concentration for PPCp (Fig. 3). A high concentration

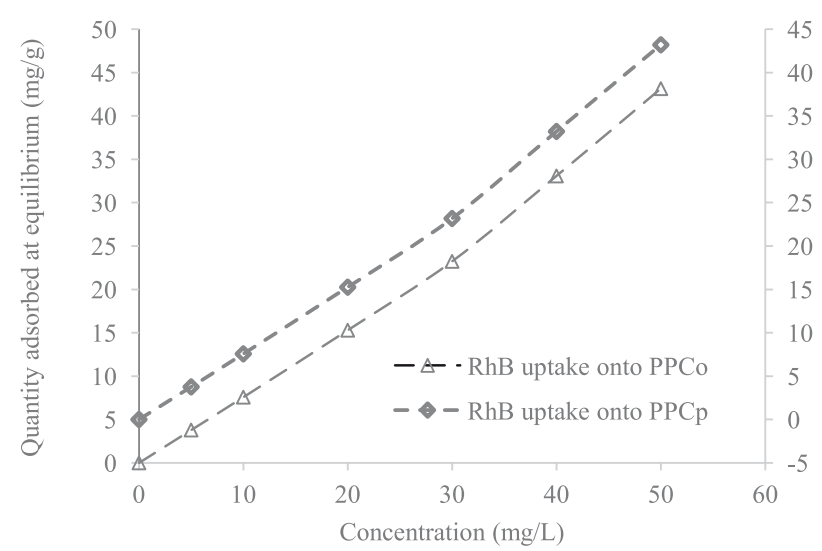

Fig. 3. Effects of concentration on RhB uptake onto PPCo and PPCp [Dosage $(0.1 \mathrm{~g})$, Temperature $\left(26^{\circ} \mathrm{C}\right)$ and agitation speed (130 rpm), $\mathrm{pH}(4)]$.

generates great driving force to overcome mass transfer barrier between the adsorbate-adsorbent interfaces, hence the increase in RhB quantity adsorption with increases in concentration. At lower concentrations, the ratio of available adsorption site to $\mathrm{RhB}$ molecules in solution was high, hence the high percentage removal was recorded while the reverse was observed at high concentration [24].

\section{Effects of Contact Time on RhB Uptake onto PPCo and PPCp}

Uptake of $\mathrm{RhB}$ was very rapid, with about $70 \%$ removal recorded within the first five minutes of adsorbent contact. Slight RhB adsorption was further recorded as contact time increased (Fig. 4). RhB molecules were readily adsorbed to the adsorbent surface, hence the rapid adsorption of $\mathrm{RhB}$ during the first five minutes of contact. Continuous bombardment of RhB molecules with the adsorbent surface also results in percolation and absorption of RhB molecules, hence the slight increase observed as contact time increased.

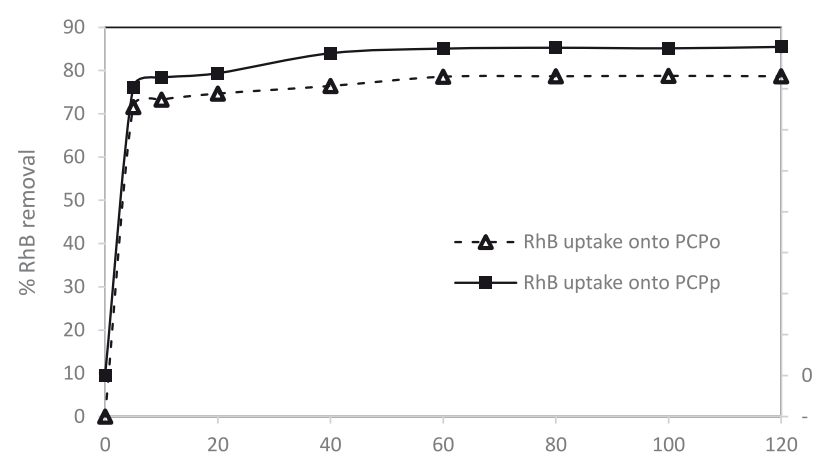

Fig. 4. Effects of contact time on RhB adsorption onto PCPo and PCPp [Dosage $(0.1 \mathrm{~g})$, Temperature $\left(26^{\circ} \mathrm{C}\right)$ and agitation speed (130 rpm), pH (4)]. 


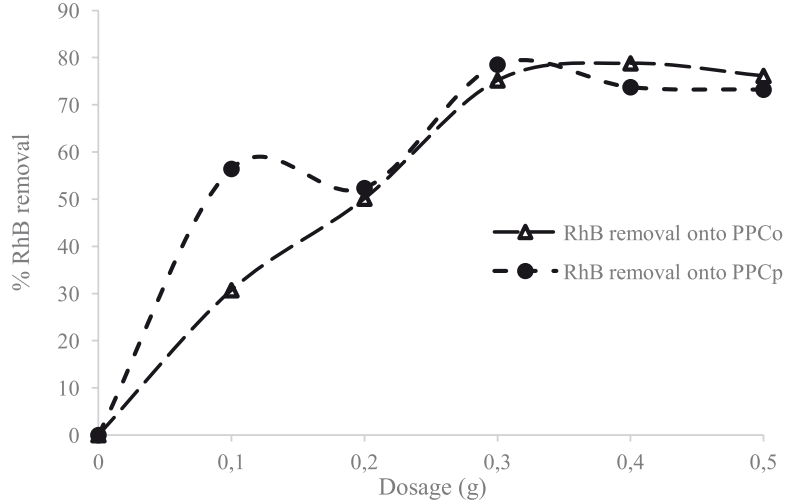

Fig. 5. Effects of adsorbent dosage on $\mathrm{RhB}$ adsorption onto PCPo and PCPp [Temperature $\left(26^{\circ} \mathrm{C}\right)$ and agitation speed (130 rpm), $\mathrm{pH}(4)]$.

\section{Effects of Adsorbent Dosage on RhB Uptake onto PPCo and PPCp}

For PPCo, RhB removal percentage gradually increased from $30.72 \%$ as adsorbent dosage increased from $0.1 \mathrm{~g}$ to $75.19 \%$ at $0.3 \mathrm{~g}$ dosage. Subsequently, a negligible increase was observed when dosage was further increased. A similar trend was observed for PPCp with $56.43 \%$ removal at $0.1 \mathrm{~g}$ and $78.54 \%$ removal at $0.3 \mathrm{~g}$, and subsequent slight decrease in percentage removal when the dosage was further increased (Fig. 5). Increases in available surface adsorption site enhanced $\mathrm{RhB}$ removal when adsorbent dosages were increased [28]. Subsequent saturation of adsorption sight as well as overlayer of adsorbents may have resulted in removal equilibrium/reduction in percentage removal [29].

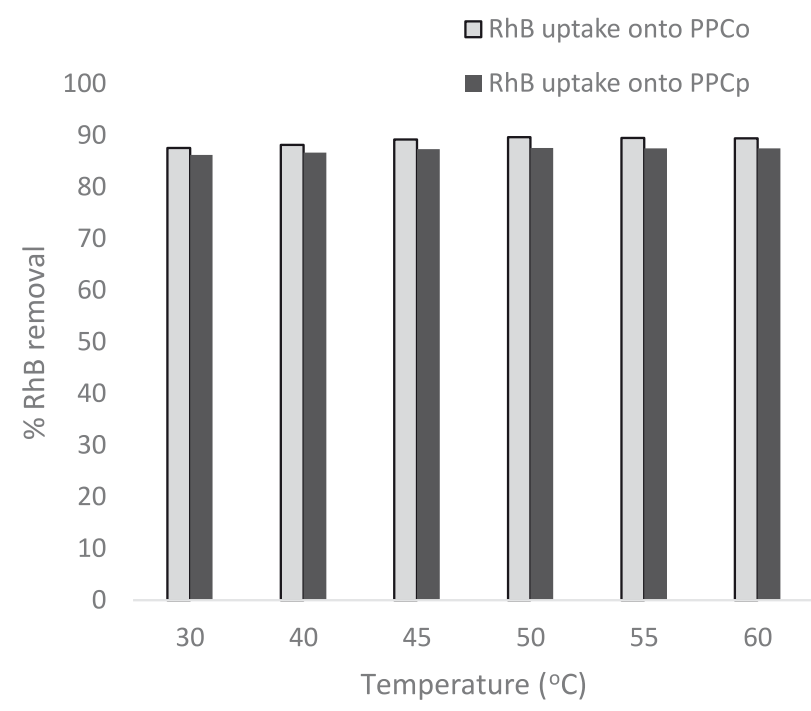

Fig. 6. Effects of temperature on RhB adsorption onto PPCo and PPCp [agitation speed (130 rpm), dosage (1 g/L), pH (4)].
Table 2. Isotherm constant for the uptake of RhB onto PPCo and PPCp.

\begin{tabular}{|c|c|c|c|}
\hline Isotherms & Constants & PPCo & PPCp \\
\hline Langmuir & $\mathrm{q}_{\text {max }}(\mathrm{mg} / \mathrm{g})$ & 7.003 & 6.878 \\
\hline \multirow{4}{*}{ Freundlich } & $\mathrm{K}_{\mathrm{L}}\left({\left.\mathrm{L} \cdot \mathrm{mg}^{-1}\right)}^{-}\right.$ & 2.496 & 4.130 \\
\cline { 2 - 4 } & $\mathrm{R}_{\mathrm{L}}$ & 0.012 & 0.011 \\
\cline { 2 - 4 } & $\mathrm{R}^{2}$ & 0.9988 & 0.9995 \\
\cline { 2 - 4 } & $\mathrm{K}_{\mathrm{F}}$ & 2.699 & 2.9854 \\
\cline { 2 - 4 } & $\mathrm{n}$ & 2.752 & 3.3003 \\
\hline \multirow{4}{*}{ Temkin } & $\mathrm{R}^{2}$ & 0.6106 & 0.5852 \\
\cline { 2 - 4 } & $\mathrm{B}$ & 1.308 & 2.007 \\
\cline { 2 - 4 } & $\mathrm{A}(\mathrm{L} / \mathrm{g})$ & 13.24 & 0.68 \\
\cline { 2 - 4 } & $\mathrm{b}(\mathrm{kJ} / \mathrm{mol})$ & 1.862 & 1.214 \\
\hline \multirow{7}{*}{$\mathrm{R}^{2}$} & 0.661 & 0.9237 \\
\hline
\end{tabular}

\section{Effects of Temperature on RhB Uptake onto PPCo and PPCp}

RhB removal by PPCo and PPCp was not vividly affected by an increase in systems temperature. A negligible increase was observed within the two systems, and an increase in adsorption system temperature may further results in activation of adsorption sites as well as an increase in solubility of adsorbate, thereby enhancing adsorption [30]. None of this seems to have occurred in the two adsorption

Table 3. Pseudo first-order, pseudo second-order and intra particle diffusion kinetic model parameters for the adsorption of RhB onto PPCo and PPCp.

\begin{tabular}{|c|c|c|}
\hline \multirow{2}{*}{ Constants } & \multicolumn{2}{|c|}{ Adsorbents } \\
\hline & PPCo & PPCp \\
\hline $\mathrm{q}_{\mathrm{e} \text { experimental }}(\mathrm{mg} / \mathrm{g})$ & 19.67 & 19.75 \\
\hline \multicolumn{3}{|c|}{ Pseudo first order } \\
\hline $\mathrm{q}_{\mathrm{e} \text { calculated }}(\mathrm{mg} / \mathrm{g})$ & 3.32 & 3.17 \\
\hline $\mathrm{K}_{1} \times 10^{-2}\left(\mathrm{~min}^{-1}\right)$ & 6.07 & 6.71 \\
\hline $\mathrm{R}^{2}$ & 0.9187 & 0.8643 \\
\hline \multicolumn{3}{|l|}{ Pseudo second order } \\
\hline $\mathrm{q}_{\mathrm{e} \text { calculated }}(\mathrm{mg} / \mathrm{g})$ & 19.96 & 19.84 \\
\hline $\mathrm{K}_{2} \times 10^{-2}\left(\mathrm{gmg}^{-1} \mathrm{~min}^{-1}\right)$ & 6.07 & 5.59 \\
\hline $\mathrm{R}^{2}$ & 0.9999 & 0.9999 \\
\hline \multicolumn{3}{|c|}{ Intra particle diffusion } \\
\hline $\mathrm{C}\left(\mathrm{mgg}^{-1}\right)$ & 17.33 & 16.27 \\
\hline $\mathrm{K}_{\text {diff }}\left(\mathrm{mgg}^{-1} \mathrm{~min}^{-1 / 2}\right)$ & 0.29 & 0.47 \\
\hline $\mathrm{R}^{2}$ & 0.9834 & 0.9174 \\
\hline
\end{tabular}


Table 4. Thermodynamic parameters for RhB uptake onto PPCo and PPCp.

\begin{tabular}{|c|c|c|c|c|c|c|c|c|}
\hline \multirow{2}{*}{ Adsorbents } & \multirow{2}{*}{$\Delta \mathrm{H}^{\mathrm{o}}(\mathrm{kJ} / \mathrm{mol})$} & \multirow{2}{*}{$\begin{array}{c}\Delta \mathrm{S}^{\circ}(\mathrm{J} / \mathrm{mol} / \mathrm{K}) \\
\text { Temperature }(\mathrm{K})\end{array}$} & \multicolumn{6}{|c|}{$\Delta \mathrm{G}^{\mathrm{o}}(\mathrm{kJ} / \mathrm{mol})$} \\
\hline & & & 303 & 313 & 318 & 323 & 328 & 333 \\
\hline PPCo & 5.99 & 24.60 & -1.46 & -1.71 & -1.83 & -1.95 & -2.07 & -2.19 \\
\hline PPCp & 3.37 & 14.90 & -1.14 & -1.29 & -1.37 & -1.44 & -1.52 & -1.59 \\
\hline
\end{tabular}

systems in the study, hence increased temperature results in negligible increase in $\mathrm{RhB}$ percentage removal (Fig. 6).

\section{Equilibrium Data Analysis}

Equilibrium adsorption data tested with three isotherms was found to fit best in the Langmuir isotherm model with correlation coefficients of 0.9988 and 0.9995 for PPCo and PPCp adsorbents, respectively. The dimensionless $R_{L}$ factors obtained for the two systems were less than unity, while the Freundlich constant $\mathrm{n}$ obtained was greater than 1 . The correlation coefficients for the Freundlich isotherms were low for the two adsorption systems, and the Temkin correlation coefficient for the RhB-PPCp system was also found to be above 0.9 (Table 2). Maximum monolayer adsorption capacity $\left(\mathrm{q}_{\max }\right)$ for the RhB-PPCo and RhB-PPCp were $7.003 \mathrm{mg} / \mathrm{g}$ and $6.878 \mathrm{mg} / \mathrm{g}$, respectively. Monolayer adsorption dominates the uptake of $\mathrm{RhB}$ onto the two adsorbents prepared, hence the high correlation coefficient obtained for Langmuir adsorption isotherm data analysis. The values of Freundlich constant $n$ and dimensionless $R_{L}$ values indicates feasible adsorption process within the two adsorption systems. The high correlation coefficient obtained for the Temkin isothermal model suggests that adsorbate-adsorbate interaction may have also occurred in the uptake of $\mathrm{RhB}$ onto PPCp.

\section{Kinetics Studies}

Correlation coefficient for the pseudo firstorder kinetics model was found to be low compared to that of the pseudo second-order kinetics model. The experimentally obtained quantity adsorbed at equilibrium $\left(\mathrm{q}_{\mathrm{e}}\right.$ experimental $)$ compared with calculated $\mathrm{q}_{\mathrm{e}}$ $\left(\mathrm{q}_{\mathrm{e} \text { calculated }}\right)$ values for pseudo first-order kinetics also vary greatly. A high degree of closeness, however, occurred between $\mathrm{q}_{e}$ experimental and $\mathrm{q}_{\mathrm{e}}$ calculated for the pseudo second-order kinetic modeling (Table 3). The intraparticle diffusion model plot also gave correlation coefficient of greater than 0.9. The pseudo second-order kinetics model better describe the mechanism of RhB uptake onto PPCo and PPCp with correlation coefficient of 0.9999 for the two adsorption systems. The greater value recorded for $\mathrm{C}$ in the intraparticle diffusion model of the RhB-PPCo system suggests that the boundary layer effect was great for the RhB-PPCo system than the RhB-PPCp system (Table 3).

\section{Thermodynamic Studies}

The $\Delta \mathrm{H}^{\circ}$ and $\Delta \mathrm{S}^{\circ}$ values for the two adsorption systems were positive, while $\Delta \mathrm{G}^{\mathrm{o}}$ values were all negative (Table 4). The negativity of $\Delta \mathrm{G}^{\circ}$ was found to increase with increased temperature. It ranged from $-1.46 \mathrm{~kJ} / \mathrm{mol}$ for $303 \mathrm{~K}$ to $-2.19 \mathrm{~kJ} / \mathrm{mol}$ for $333 \mathrm{~K}$ for PPCo and $-1.14 \mathrm{~kJ} / \mathrm{mol}$ for $303 \mathrm{~K}$ to $-1.59 \mathrm{~kJ} / \mathrm{mol}$ for $333 \mathrm{~K}$ for PPCp. The adsorption process was endothermic with an increase in degree of randomness between the solid adsorbent surface and liquid adsorbate. Adsorption process spontaneity and favourability increased as temperature increased from $303 \mathrm{~K}$ to $333 \mathrm{~K}$.

\section{Cost Analysis}

Plantain peel is a waste that is usually discarded and hence available at no cost. The cost of collection, pretreatment and activation summed up to 14.02 USD $/ \mathrm{kg}$ and $2.98 \mathrm{USD} / \mathrm{kg}$. The use of this waste in PPCp and PPCo preparation reduced cost by half and 12 times, respectively, when compared with commercial activated carbon [31]. The percentage of RhB removal was as high at $95 \%$ for the lowest $\mathrm{RhB}$ concentration studied.

\section{Conclusions}

Prepared adsorbents were effective for $\mathrm{RhB}$ uptake from aqueous solution. Monolayer adsorption dominates the uptake of RhB onto PPCo and PPCp, while some adsorbate-adsorbate interactions also occurred in the RhB-PPCp adsorption system. Pseudo second-order kinetics best described the kinetics of the adsorption system. High temperature better favoured RhB uptake onto the two adsorbents, thus suggesting that PPCo and PPCp will be effective in treating hot dye-laden effluent.

\section{Conflict of Interest}

The authors declare no conflict of interest.

\section{References}

1. SATTAR M., HAYEEYE F., CHINPA W., SIRICHOTE O. Preparation and characterization of poly (lactic acid)/ activated carbon composite bead via phase inversion method and its use as adsorbent for Rhodamine $\mathrm{B}$ in 
aqueous solution. J. of Environ. Chem. Eng. 5, 3780, 2017.

2. SAINI J., GARG,V.K., GUPTA R.K., KATARIA N. Removal of Orange $G$ and Rhodamine $B$ dyes from aqueous system using hydrothermally synthesized zinc oxide loaded activated carbon ( $\mathrm{ZnO}-\mathrm{AC})$. J. of Environ. Chem. Eng. 5, 884, 2017.

3. HUANG Y., ZHENG X., FENG S., GUO Z., LIANG S. Enhancement of rhodamine $B$ removal by modifying activated carbon developed from Lythrum salicaria L. with pyruvic acid. Colloids and Surfaces A: Physicochem. Eng. Aspects. 489, 154, 2016.

4. PTASZKOWSKA-KONIARZ M., GOSCIANSKA J., PIETRZAK R. Removal of rhodamine B from water by modified carbon xerogels. Colloids and Surfaces A 543, 109, 2018.

5. INYINBOR A.A., ADEKOLA F.A., OLATUNJI G.A. EDTA modified Irvingia gabonensis: An efficient bioresource material for the removal of Rhodamine B. Pakistan J. of Anal. and Environ. Chemistry. 16 (2), 38, 2015.

6. HAYEEYE F., SATTAR M., CHINPA W., SIRICHOTE O. Kinetics and thermodynamics of Rhodamine B adsorption by gelatin/activated carbon composite beads. Colloids and Surfaces A: Physicochem. Eng. Aspects 513, 259, 2017.

7. LAM S.S., LIEW R.K., WONG Y.M., YEK P.N.Y., MA N.L., LEE C.L., CHASE H.A. Microwave-assisted pyrolysis with chemical activation, an innovative method to convert orange peel into activated carbon with improved properties as dye adsorbent; Journal of Cleaner Production. 162, 1376, 2017.

8. LI Z., DENG H., YANG L., ZHANG G., LI Y., REN $Y$. Influence of potassium hydroxide Activation on characteristics and environmental risk of heavy metals in chars derived from municipal sewage sludge. Bioresour Technol. 256, 216, 2018.

9. DANISH M., AHMAD T., HASHIM R., SAID N., AKHTAR M.N., MOHAMAD-SALEH J., SULAIMAN O. Comparison of surface properties of wood biomass activated carbons and their application against rhodamine $\mathrm{B}$ and methylene blue dye. Surfaces and Interfaces 11, 1, 2018.

10. AZHARUL ISLAM MD., SABAR S., BENHOURIA A., KHANDAY W.A., ASIF M., HAMEED B.H. Nanoporous activated carbon prepared from karanj (Pongamia pinnata) fruit hulls for methylene blue adsorption; Journal of the Taiwan Institute of Chemical Engineers 74, 96, 2017.

11. LIEW R.K., AZWAR E., YEK P.N.Y., LIM X.Y., CHENG C.K., NG J., JUSOH A., LAM W.H., IBRAHIM M.D., MA N.L., LAM S.S. Microwave pyrolysis with $\mathrm{KOH} / \mathrm{NaOH}$ mixture activation: A new approach to produce micromesoporous activated carbon for textile dye adsorption; Bioresource Technology, 266, 1, 2018.

12. BRITO M.J.P., VELOSO C.M., SANTOS L.S., BONOMO R.C.F., FONTAN R.D.I. Adsorption of the textile dye Dianix ${ }^{\circledR}$ royal blue $\mathrm{CC}$ onto carbons obtained from yellow mombin fruit stones and activated with $\mathrm{KOH}$ and $\mathrm{H}_{3} \mathrm{PO}_{4}$ : Kinetics, adsorption equilibrium and thermodynamic studies. Powder Technology (2018), doi:10.1016/j. powtec.2018.08.017

13. ARAGA R., SONI S., SHARMA C.S. Fluoride adsorption from aqueous solution using activated carbon obtained from $\mathrm{KOH}$-treated jamun (Syzygium cumini) seed; Journal of Environmental Chemical Engineering 5, 5608, 2017.

14. LANGMUIR I. The constitutional and fundamental properties of solids and liquids. J. Am. Chem. Soc. 38, 2221, 1916.
15. FREUNDLICH H.M.F. Over the adsorption in solution. Z. Phys. Chem. 57, 385, 1906.

16. TEMKIN M.I., PYZHEV V. Kinetics of ammonia synthesis on promoted iron catalyst, Acta Physiochimica USSR, 12, 327, 1940.

17. LAGERGREN S., SVENSKA B.K. On the theory of socalled adsorption of materials. R. Swed. Acad. Sci. Doc, Band, 24, 1, 1898.

18. HO Y.S., MCKAY G. Pseudo-second order model for sorption processes, Proc. Biochem. 34, 451, 1999.

19. WEBER W.J., MORRIS J.C. Kinetics of adsorption on carbon from solution, J. Sanity Eng. Div. Am. Soc. Civil Eng. 89, 31, 1963.

20. ADHIKARI S., MANDAL S., SARKAR D., KIM D., MADRAS G. Kinetics and mechanism of dye adsorption on WO3 nanoparticles; Applied Surface Science 420, 472, 2017.

21. GUPTA H., SINGH S. Kinetics and thermodynamics of phenanthrene adsorption from water on orange rind activated carbon; Environment Technology and Innovation; 10, 208, 2018.

22. LI Z., RANA D., WANG Z., MATSUURA T., LAN C.Q. Synergic effects of hydrophilic and hydrophobic nanoparticles on performance of nanocomposite distillation membranes: An experimental and numerical study; Separation and Purification Technology; 202, 45, 2018.

23. INYINBOR A.A., ADEKOLA F.A., OLATUNJI G.A. Liquid phase adsorption of Rhodamine B onto acid treated Raphia hookerie epicarp: Kinetics, Isotherm and thermodynamics studies; S. Afr. J. of Chem. 69, 218, 2016.

24. INYINBOR A.A., ADEKOLA F.A., OLATUNJI G.A. Liquid phase adsorptions of Rhodamine $B$ dye onto raw and chitosan supported mesoporous adsorbents: isotherms and kinetics studies; Appl. water Sci. 7, 2297, 2017. http:// link.springer.com/article/10.1007/s13201-016-0405-4

25. INYINBOR A.A., ADEKOLA F.A., OLATUNJI G.A. Adsorption of Rhodamine B dye from aqueous solution on Irvingia gabonensis biomass: Kinetics and thermodynamics studies; S. Afr. J. of Chem. 68, 115, 2015.

26. BHATTACHARYYA K.G, SENGUPTA S., SARMA G.K. Interactions of the dye, Rhodamine B with kaolinite and montmorillonite in water. Appl Clay Sci. 99, 7, 2014.

27. MA L., XI Y., HE H., AYOKO G.A., ZHU R., ZHU J. Efficiency of Fe-montmorillonite on the removal of Rhodamine B and hexavalent chromium from aqueous solution. Appl Clay Sci. 120, 9, 2016.

28. ANGIN D. Utilization of activated carbon produced from fruit juice industry solid waste for the adsorption of Yellow 18 from aqueous solution,. Bioresour Technol. 168, 259, 2014

29. PIRBAZARI A.E., SABERIKHAH E., HABIBZADEHKOZANI S.S. $\mathrm{Fe}_{3} \mathrm{O}_{4}$ - wheat straw: preparation, characterization and its application for methylene blue adsorption. Water Resour Ind 7-8, 23, 2014.

30. INYINBOR A.A., ADEKOLA F.A., OLATUNJI G.A. Kinetic and thermodynamic modeling of liquid phase adsorption of Rhodamine B dye onto Raphia hookerie fruit epicarp; Water Resour and Ind, 15, 14, 2016.

31. BELLO O.S., AHMAD M.A. Response surface modeling and optimization of remazol brilliant blue reactive dye removal using periwinkle shell-based activated carbon, Sep. Sci. Technol. 46, 2367, 2011. 